\title{
Functional outcome and morbidity after microsurgical resection of spinal meningiomas
}

\author{
Fatma Kilinc, MD, ${ }^{1}$ Matthias Setzer, MD, ${ }^{1}$ Gerhard Marquardt, MD, PhD, ${ }^{1}$ Fee Keil, MD, ${ }^{2}$ \\ Daniel Dubinski, MD, ${ }^{1}$ Markus Bruder, MD, ${ }^{1}$ Volker Seifert, MD, PhD, ${ }^{1}$ and Bedjan Behmanesh, MD ${ }^{1}$ \\ Departments of ${ }^{1}$ Neurosurgery and ${ }^{2}$ Neuroradiology, Goethe-University, Frankfurt am Main, Germany
}

\begin{abstract}
OBJECTIVE The aim of this study was to evaluate functional outcome, surgical morbidity, and factors that affect outcomes of surgically treated patients.

METHODS The authors retrospectively analyzed patients who underwent microsurgical resection for spinal meningiomas between 2009 and 2020. Patient data and potential variables were collected and evaluated consecutively. Functional outcomes were evaluated using univariate and multivariate analyses.
\end{abstract}

RESULTS A total of 119 patients underwent microsurgical resection of spinal meningioma within the study period. After a mean follow-up of $25.4 \pm 37.1$ months, the rates of overall complication, tumor recurrence, and poor functional outcome were $9.2 \%, 7.6 \%$, and $5 \%$, respectively. Age, sex, revision surgery, and tumor recurrence were identified as independent predictors of poor functional outcome. Obesity and surgeon's experience had an impact on the complication rate, whereas extent of resection and tumor calcification affected the rate of tumor recurrence.

CONCLUSIONS Microsurgical resection of spinal meningiomas remains safe. Nevertheless, some aspects, such as obesity and experience of the surgeons that result in a higher complication rate and ultimately affect clinical outcome, should be considered when performing surgery.

https://thejns.org/doi/abs/10.3171/2021.2.FOCUS201116

KEYWORDS spinal meningiomas; clinical outcome; complications; tumor recurrence

$\mathrm{M}$ ENINGIOMAS are the most common type of tumor that arise from arachnoid cells in the CNS. Spinal meningiomas account for approximately $12 \%$ of all meningiomas and are one of the most common intradural extramedullary spinal tumors, representing $25 \%-30 \%$ of all spinal tumors. The overall incidence of spinal meningioma is approximately $0.31-0.35$ per 100,000 population. Meningiomas occur more often in women than in men and have a peak incidence in the 6th through 8th decades of life. ${ }^{1-6}$

Risk factors, such as hereditary syndromes, environmental exposure to high-dose ionizing radiation, especially in childhood and prior trauma, are discussed to be associated with occurrence of meningiomas. ${ }^{7,8}$ Progressive spinal cord compression caused by spinal meningiomas leads to neurological deficits and influences functional outcome and quality of life. In this study, we report our experience with surgically treated patients for microsurgical resection of spinal meningiomas.

\section{Methods}

The study included all patients who underwent microsurgical resection of spinal meningioma between 2009 and 2020. Based on the aim of the study, only meningiomas below the foramen magnum were included and evaluated.

Information, including patient characteristics, radiological features, diabetes mellitus, arterial hypertension, BMI, initial symptoms, tumor location, number of affected spinal levels, surgical approach, surgeon experience (defined as $<10$ and $>10$ procedures having been previously performed), American Society of Anesthesiologists (ASA) Physical Classification, surgical time (time from skin incision to wound closure), length of hospital stay, and functional neurological status at admission and during the course of treatment, was recorded and further analyzed. The neurological status pre- and postoperatively at discharge as well as at follow-up at least 6 months postoperatively and at a later follow-up, were assessed using the Eastern Cooperative Oncology Group (ECOG) score

ABBREVIATIONS ASA = American Society of Anesthesiologists; ECOG = Eastern Cooperative Oncology Group; EOR = extent of resection.

SUBMITTED December 31, 2020. ACCEPTED February 17, 2021.

INCLUDE WHEN CITING DOI: 10.3171/2021.2.FOCUS201116. 
TABLE 1. ECOG performance status

\begin{tabular}{cl}
\hline Grade & ECOG \\
\hline 0 & "Fully active, able to carry on all pre-disease performance without restriction" \\
\hline 1 & $\begin{array}{c}\text { "Restricted in physically strenuous activity but ambulatory and able to carry out work of a light or sedentary nature, e.g., light house work, } \\
\text { office work" }\end{array}$ \\
\hline 2 & "Ambulatory and capable of all selfcare but unable to carry out any work activities. Up and about more than 50\% of waking hours" \\
\hline 3 & "Capable of only limited selfcare, confined to bed or chair more than 50\% of waking hours" \\
\hline 5 & "Completely disabled. Cannot carry on any selfcare. Totally confined to bed or chair" \\
\hline
\end{tabular}

From Oken, Martin, Creech, Richard, Tormey, Douglass, et al. Toxicity and response criteria of the Eastern Cooperative Oncology Group. Am J Clin Oncol. 1982;5(6):649-656. Cited in: Journals@Ovid Full Text at http://ovidsp.ovid.com/ovidweb.cgi?T=JS\&PAGE=reference\&D=ovfta\&NEWS=N\&AN=00000421-19821200000014. Accessed March 16, 2021.

describing patient ability and level of neurological independence (Table 1). ${ }^{9}$

Surgery was performed using a standard dorsal approach with laminectomy or hemilaminectomy. In selected cases with multilevel tumor involvement, a laminoplasty was performed instead. The extent of resection (EOR) was classified according to the Simpson grading system. ${ }^{10}$ The amount of tumor resection was rated as total resection (Simpson grade I or II), subtotal resection (Simpson grade IV), or biopsy (Simpson grade V); no case of Simpson grade III resection was seen on review of the surgical reports. The EOR was assessed by the surgical report as recorded by the surgeon and on early postoperative MRI ( $<72$ hours). Somatosensory evoked potentials and motor evoked potentials were routinely monitored throughout surgery. Important variables of interest in the present study were functional outcome, complications, and recurrence rate. Good outcome was defined as stable ECOG score or improvement in ECOG score in comparison with the condition at admission. Complications were defined as any adverse event that resulted in a surgical procedure to revise or treat the complications, including superficial or deep wound infection, epidural and/or subdural hematoma, CSF leak, deep venous thrombosis, pulmonary embolism, and postoperative mortality. The recurrence rate was analyzed to define predictive factors influencing the recurrence rate. This study was approved by the local ethics committee at our institution.

\section{Statistical Analysis}

All statistics were performed using IBM SPSS (version 21, IBM Corp.); $\mathrm{p}<0.05$ was considered significant. Comparison of important differences between the study groups was made using Fisher's exact test for categorical variables. Nonparametric tests included the Mann-Whitney U-test and Kruskal-Wallis test to compare groups of data that did not follow the normal distribution. Tests for normality were performed using the Shapiro-Wilk test. Univariate analysis was performed to determine the effect of clinical variables on long-term outcome. In a second step, a multivariate analysis was performed to find independent predictors of long-term outcome after surgical treatment of intraspinal meningiomas by using a backward stepwise binary logistic regression analysis. For this step, the dependent variables of functional outcome and neurological outcome, complications, and tumor recurrence were dichotomized.

\section{Results}

\section{Patient Characteristics}

Ultimately, 119 patients (mean age $59.9 \pm 14.8$ years, range $25-85$ years) were included for final analysis. The sex distribution revealed a female predominance, consisting of $70.6 \%$ females, with a female-to-male ratio of 2.5:1. The mean follow-up was $25.4 \pm 37.1$ months. The most frequently involved location was the thoracic region $(68.9 \%)$, followed by the cervical region $(24.4 \%)$. Furthermore, in more than $70 \%$ of patients, the tumor affected only 1 spinal level and in $28.6 \%, 2$ spinal levels; multilevel extension of more than 2 levels was only seen in 1 patient. The most common symptom that led to patient presentation was sensory deficit (34.5\%), followed by gait instability (26.9\%) and motor deficit (21\%). Back pain and radicular pain were apparent in $27.7 \%$ of patients. Regarding initial symptoms and complaints, almost $72 \%$ of patients revealed a good status according to their ECOG grade (0 and 1); ambulatory and capable of all self-care but unable to carry out any work activities induced by spinal meningiomas was seen in almost $23 \%$ patients, whereas only $5 \%$ were capable of only limited self-care. The meningioma was accessed by a laminectomy in $78.2 \%$, by a hemilaminectomy in $19.3 \%$, and by a laminoplasty in 2 patients. Complete resection (Simpson grades I and II) was achieved in $86.6 \%$ and subtotal resection (Simpson grades IV and V) in $13.4 \%$. Data regarding tumor calcification were obtained from surgical reports; $87 \%$ of patients had no calcification, $10.9 \%$ had partial calcification, and $1.7 \%$ had complete calcification. An overview is given in Table 2.

\section{Complications}

The overall complication rate in our investigated patient population was $9.2 \%$ (11 patients). In detail, postoperative complications consisted of postoperative infection in 2 patients (18.2\%), CSF leak in 7 patients (63.6\%), and postoperative epidural hematoma with subsequent need for revision surgery and postoperative pulmonary embolism in 1 patient each $(0.8 \%)$. Because of postoperative 
TABLE 2. Patient characteristics

\begin{tabular}{|c|c|}
\hline & Value \\
\hline \multicolumn{2}{|l|}{ Sex } \\
\hline Female & $84(70.6)$ \\
\hline Male & $35(29.4)$ \\
\hline Mean age, yrs & 59.9 \\
\hline \multicolumn{2}{|l|}{ Tumor location } \\
\hline Cervical & $29(24.4)$ \\
\hline Cervicothoracic & $4(3.4)$ \\
\hline Thoracic & $82(68.9)$ \\
\hline Thoracolumbar & $1(0.8)$ \\
\hline Lumbar & $3(2.5)$ \\
\hline \multicolumn{2}{|l|}{ Affected level } \\
\hline 1 & $84(70.6)$ \\
\hline 2 & $34(28.6)$ \\
\hline$>2$ & $1(0.8)$ \\
\hline \multicolumn{2}{|l|}{ Symptoms \& signs } \\
\hline Back pain & $11(9.2)$ \\
\hline Radicular pain & $22(18.5)$ \\
\hline Sensory deficit & $41(34.5)$ \\
\hline Motor weakness & $25(21.0)$ \\
\hline Bladder/bowl dysfunction & $9(7.6)$ \\
\hline Gait ataxia & $32(26.9)$ \\
\hline Incidental finding & $3(2.5)$ \\
\hline Lower-limb spasticity & $6(5.0)$ \\
\hline Diabetes & $14(11.8)$ \\
\hline Hypertension & $49(41.2)$ \\
\hline Obesity & $21(17.6)$ \\
\hline Mean BMl, kg/m² & 27.0 \\
\hline Prior surgery & $9(7.6)$ \\
\hline \multicolumn{2}{|l|}{ ECOG grade on admission } \\
\hline 0 & 38 (31.9) \\
\hline 1 & $48(40.3)$ \\
\hline 2 & $27(22.7)$ \\
\hline 3 & $6(5.0)$ \\
\hline \multicolumn{2}{|l|}{ Histology } \\
\hline WHO grade I & 0 \\
\hline Meningothelial & $93(78.2)$ \\
\hline Psammomatous & $9(7.6)$ \\
\hline Transitional & $4(3.4)$ \\
\hline Fibrous & $3(2.5)$ \\
\hline Choroid & $2(1.7)$ \\
\hline Angioma & $1(0.8)$ \\
\hline WHO grade II & $7(5.9)$ \\
\hline \multicolumn{2}{|l|}{ Calcification } \\
\hline None & $104(87.4)$ \\
\hline Partial & $13(10.9)$ \\
\hline Complete & $2(1.7)$ \\
\hline \multicolumn{2}{|l|}{ EOR } \\
\hline GTR & 103 (86.6) \\
\hline STR & $16(13.4)$ \\
\hline
\end{tabular}

CONTINUED IN NEXT COLUMN »
» CONTINUED FROM PREVIOUS COLUMN

TABLE 2. Patient characteristics

\begin{tabular}{|c|c|}
\hline & Value \\
\hline Mean surgical time, mins & 185 \\
\hline \multicolumn{2}{|l|}{ Surgical approach } \\
\hline Laminectomy & $93(78.2)$ \\
\hline Hemilaminectomy & $23(19.3)$ \\
\hline Laminoplasty & $2(1.7)$ \\
\hline Mean LOS, days & 7.7 \\
\hline \multicolumn{2}{|l|}{ ASA class } \\
\hline 1 & $8(6.7)$ \\
\hline$\|$ & $76(63.9)$ \\
\hline III & $33(27.7)$ \\
\hline IV & $1(0.8)$ \\
\hline \multicolumn{2}{|l|}{ Dural attachment } \\
\hline Ventral & $8(6.7)$ \\
\hline Ventrolateral & $24(20.2)$ \\
\hline Lateral & $73(61.3)$ \\
\hline Dorsolateral & $9(7.6)$ \\
\hline Dorsal & $2(1.7)$ \\
\hline \multicolumn{2}{|l|}{ Surgeon's experience } \\
\hline$<10$ procedures & $14(11.8)$ \\
\hline$>10$ procedures & 105 (88.2) \\
\hline \multicolumn{2}{|l|}{ ECOG grade at end of FU } \\
\hline 0 & $94(79)$ \\
\hline 1 & $19(16)$ \\
\hline 2 & $5(4.2)$ \\
\hline 3 & 0 \\
\hline 4 & $1(0.8)$ \\
\hline \multicolumn{2}{|l|}{ Neurological status } \\
\hline Improved & $72(60.5)$ \\
\hline Stable & $41(34.5)$ \\
\hline Deteriorated & $6(5.0)$ \\
\hline Recurrence & $9(7.6)$ \\
\hline
\end{tabular}

FU = follow-up; GTR = gross-total resection; LOS = length of stay; STR = subtotal resection.

Values represent the number of patients (\%) unless stated otherwise.

complications, 9 revision surgeries were necessary. There was no 30-day postoperative mortality (Table 3 ).

Obesity $(\mathrm{p}=0.04)$, surgeon experience with performing $<10$ previous procedures $(\mathrm{p}<0.001)$, previous surgery $(p=0.009)$, and revision surgery $(p<0.001)$ were significantly different in patients with and those without postoperative complications. Further analysis revealed that the mean initial surgical time in patients with a postoperative CSF leak was significantly longer than that in patients without a postoperative CSF leak (219.6 vs 181.6 minutes, $\mathrm{p}=$ 0.003; Mann-Whitney U-test; Fig. 1).

We conducted a multivariate logistic regression analysis to identify independent predictors. The multivariate analysis identified surgeon experience (OR 1.1, 95\% CI 0.3-13.1) and obesity (OR 3.2 CI 1.1-8.9) as indepen- 
TABLE 3. Complication rate

\begin{tabular}{lc}
\hline & No. of Patients $(\%)$ \\
\hline 30-day mortality & 0 \\
\hline Postop infection & $2(1.7)$ \\
\hline CSF leakage & $7(5.9)$ \\
\hline Postop hematoma & $1(0.8)$ \\
\hline Neurological deterioration & $6(5.0)$ \\
\hline Pulmonary embolism & $1(0.8)$ \\
\hline
\end{tabular}

dent predictors for having a postoperative complication (Nagelkerke $\mathrm{R}^{2}=0.51$; Table 4).

\section{Outcome}

After a mean follow-up of 25.5 months, 94 patients (79\%) had an ECOG grade of 0,19 patients $(16 \%)$ had an ECOG grade of 1, and 5 patients (4\%) had an ECOG grade of 2 (restrictions in activities of daily life). Only 1 patient had an ECOG grade of 4 (completely disabled) at the end of the follow-up period. Comparing the neurological status at admission and at the end of follow-up, an improvement was observed in 72 patients $(60.5 \%)$, stable neurological status was recorded in 41 patients (35\%), and deterioration in neurological status occurred in 6 patients $(5 \%)$.

After dichotomizing the variable of functional outcome (ECOG grade at the end of follow-up), significant differences were found in the univariate analysis for the following variables in comparing the good and poor outcome groups: obesity $(\mathrm{p}=0.05)$, EOR (Simpson grade $\geq \mathrm{IV}, \mathrm{p}$ $<0.001)$, ASA class $(\mathrm{p}=0.002)$, tumor localization in the lumbar spine $(\mathrm{p}<0.002)$, previous surgery $(\mathrm{p}=0.01)$, revision surgery $(\mathrm{p}=0.03)$, and male sex $(\mathrm{p}=0.03)$. Moreover, an age-dependent influence on outcome was found (ECOG grade 0 , mean age 56.8 years; ECOG grade 1 , mean age 70.9 years; ECOG grade 2 , mean age 74.6 years; and ECOG grade 4 , mean age 59 years; $p=0.002$, Kruskal-Wallis test; Fig. 2). The length of stay in patients with ECOG grade $>0$

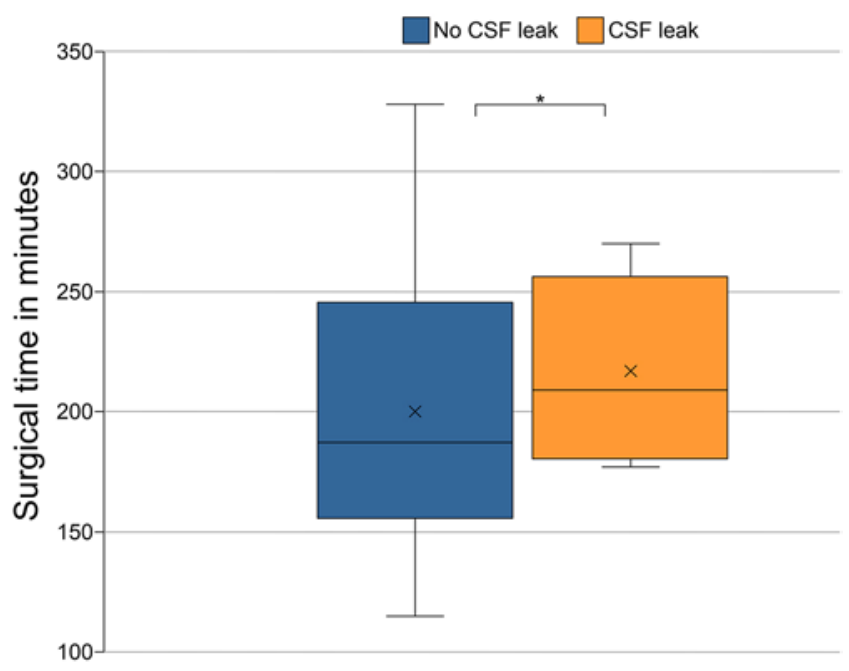

FIG. 1. Boxplot showing the effect of surgical time on postoperative CSF leakage. The $x$ indicates the mean. ${ }^{*} p=0.003$.
TABLE 4. Univariate and multivariate analysis of variables affecting overall complication rate, outcome, and tumor recurrence

\begin{tabular}{lcc}
\hline & $\begin{array}{c}\text { Univariate Analysis: } \\
p \text { Value }\end{array}$ & $\begin{array}{c}\text { Multivariate Analysis: } \\
\text { OR }(95 \% \mathrm{Cl})\end{array}$ \\
\hline Complication & & \\
\hline Obesity & 0.04 & $3.2(1.1-8.9)$ \\
\hline Surgeon's experience & $<0.001$ & $1.1(0.3-13.1)$ \\
\hline Previous surgery & 0.009 & \\
\hline Outcome & & \\
\hline Obesity & 0.05 & \\
\hline Simpson grade $\geq \mathrm{IV}$ & $<0.001$ & \\
\hline ASA class & 0.002 & $23.8(2.2-26.2)$ \\
\hline Tumor in lumbar spine & $<0.002$ & $6.0(0.8-56.7)$ \\
\hline Previous surgery & 0.01 & $1.1(0.9-1.2)$ \\
\hline Revision surgery & 0.03 & $28.6(2.2-37.4)$ \\
\hline Sex (male) & 0.03 & \\
\hline Age & 0.002 & $16.3(1.2-250)$ \\
\hline Tumor recurrence & & $8.7(0.9-87.5)$ \\
\hline Tumor recurrence & &
\end{tabular}

was significantly longer ( 7.2 days for grade $1,8.0$ days for grade 2 , and 14.4 days for grade $3 ; \mathrm{p}=0.04$; Fig. 3 ).

The multivariate relationships were analyzed for the dependent (dichotomized) variables of functional outcome and neurological outcome at the end of the followup. Among risk factors, the variables age (OR 1.1, 95\% CI $0.9-1.2$ ), sex (OR 6.0,95\% CI 0.8-56.7), revision surgery (OR 23.8, 95\% CI 2.2-26.2), and tumor recurrence (OR $28.6,95 \%$ CI 2.2-37.4) remained significant (Nagelkerke $\left.\mathrm{R}^{2}=0.43\right)($ Table 4).

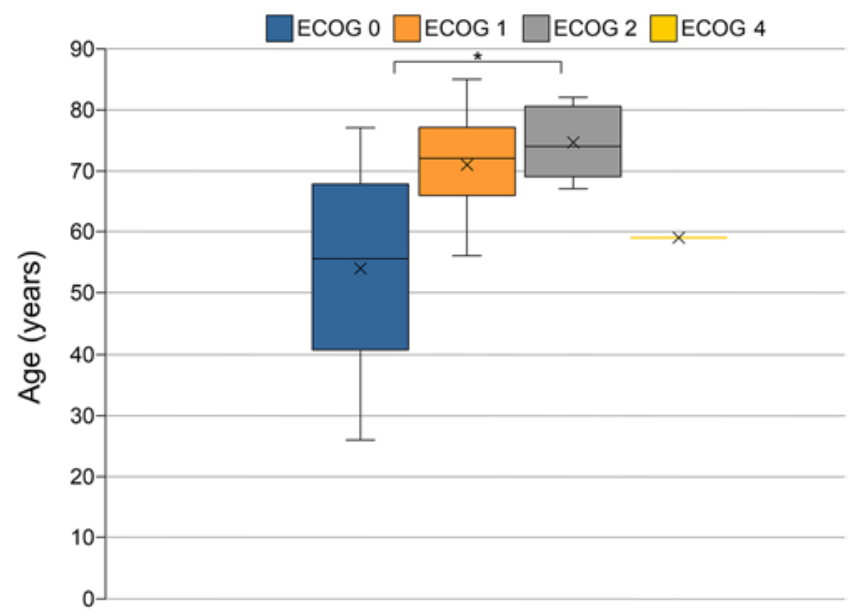

FIG. 2. Boxplot showing age-dependent outcomes. The mean age for patients with an ECOG grade of 0 was 56.8 years; for ECOG grade 1 , 70.9 years; for ECOG grade 2, 74.6 years; and for ECOG grade 4, 59 years. ${ }^{*} p=0.002$. 


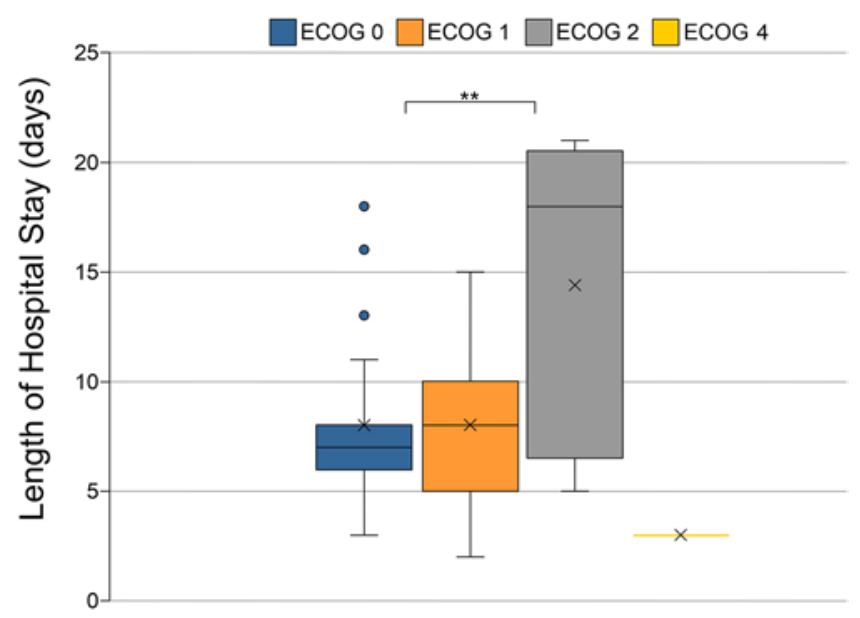

FIG. 3. Boxplot showing the relationship between length of hospital stay and clinical outcome. ${ }^{* *} p=0.04$.

\section{Meningioma Recurrence}

The recurrence rate in the present study was $7.6 \%$ (9 patients) and occurred during a mean time of 10.1 years (range 1-29 years). In univariate analysis comparing tumor recurrence and no recurrence, calcification $(\mathrm{p}=0.006)$ and EOR, namely Simpson grade IV in 15 patients and Simpson grade $\mathrm{V}$ in 1 patient $(\mathrm{p}<0.001)$ were found to be statistically significant. Furthermore, recurrence was associated with significant impact on clinical outcome, ECOG grade $>1$ during follow-up $(\mathrm{p}=0.05)$, and poor clinical outcome $(\mathrm{p}=0.01)$. Most recurrent meningiomas occurred during a longer follow-up period. Age, sex, obesity, diabetes, surgeon experience, dural attachment, localization, histology, and EOR had no impact on tumor recurrence.

In multivariate analysis, only the Simpson grade $\geq$ IV (OR 8.7, 95\% CI 0.9-87.5) and tumor calcification, which was reported in 15 patients (OR 16.3, 95\% CI 1.2-250), remained significant $\left(\right.$ Nagelkerke $\left.R^{2}=0.31\right)($ Table 4).

\section{Discussion}

The aim of the present study was to evaluate the clinical outcomes after microsurgical resection of spinal meningiomas. Furthermore, we aimed to find predictive factors affecting the complication and recurrence rates of these benign, slow-growing tumors.

In comparison with previously published data, we found some similarities and differences. The peak incidence of meningiomas occurs between the 6th and 8th decades of life..$^{11,12}$ Moreover, in contrast to other CNS tumors, there is a strong female predominance. ${ }^{8,13,14}$ The mean age in the present study was 59.8 years, with $54 \%$ of patients older than 60 years. Furthermore, there was no significant difference in mean age between males $(60.3$ years) and females (59.6 years). The female-to-male ratio in the present study was 2.5:1, which represents a relatively lower female-to-male ratio than that described in most published studies. ${ }^{6,15,16}$

\section{Complications}

The overall complication rate in the literature has been

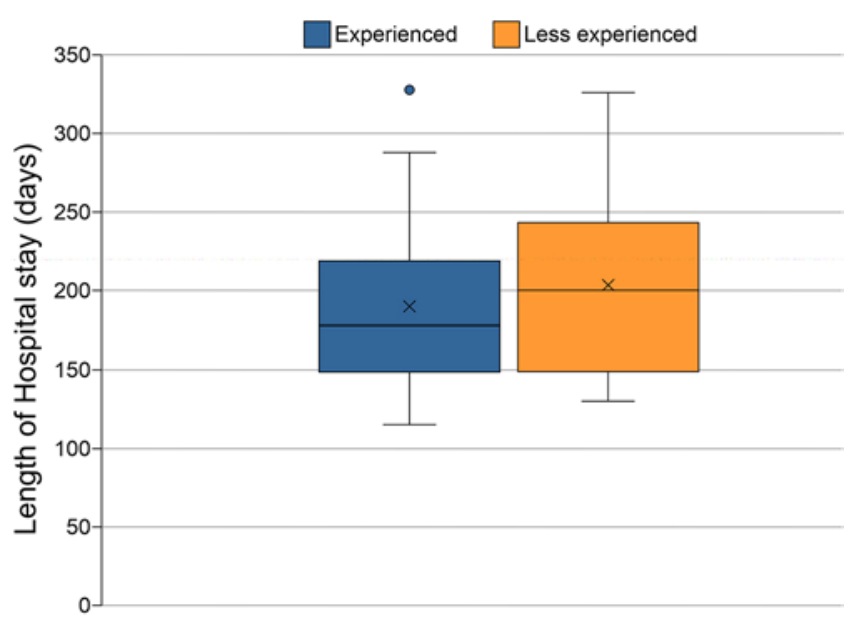

FIG. 4. Boxplot showing the difference in surgical time between experienced and less experienced surgeons.

reported to range between $0 \%$ and $24 \%$, and the most frequent complications are CSF leaks, fistulas, neurological deterioration, venous thromboembolic diseases, cardiac and respiratory complications, and infectious complications. , $^{8-14,17-25}$ We have provided additional information and show that obese patients experienced postoperative complications more often, and, more importantly, the amount of experience of the surgeon performing the procedure also affected the complication rate. These aspects have not previously been mentioned and should be considered when planning microsurgical resection. Additional training in spine and microsurgical technique may be helpful before performing surgery on spinal meningiomas. Nevertheless, the surgeon's effect and the level of experience remain an aspect that need special consideration.

Obesity influences outcomes of patients undergoing spine surgery, especially those with complications, such as surgical site infections, venous thromboembolism, major complications, prolonged length of surgery, and increased financial costs. ${ }^{26-28}$ Weight reduction prior to planned surgery, when appropriate, should be recommended for patients with mild or absent symptoms attributable to spinal meningiomas to ensure a reduced rate of postoperative complications. The length of surgery was associated with the occurrence of CSF leak. Patients with a longer surgical time significantly more often experienced postoperative CSF leakage. The mean surgical time for experienced surgeons was shorter but not significantly reduced compared with that of surgeons with less experience (182.8 vs 203.4 minutes) (Fig. 4).

\section{Recurrence Rate}

The recurrence rate of spinal meningiomas ranges from $1.3 \%$ to $6.4 \%$. In our series, the recurrence rate was $7.6 \%$; interestingly, all recurrences were in WHO grade I meningiomas, which is in contrast to previously published data, reporting a high recurrence rate for high-grade meningiomas. ${ }^{8,18,20}$ Many factors associated with tumor recurrence have been discussed in similar literature, including tumor location, Simpson resection grade, histol- 
ogy, calcification, dural attachment, and proliferative activity. $8,11,21,25$ An increased incidence of tumor recurrence with a longer follow-up period has been reported in many studies evaluating long-term follow-up. ${ }^{22,29}$ In line with this finding, we can prove this aspect. Most recurrences happened during a longer follow-up period, which was significantly longer than that in patients without tumor recurrence. Considering this fact, the rate of tumor recurrence will be higher during a longer follow-up. We found no correlation with respect to dural attachment, localization of the tumor, number of affected spinal levels, BMI, diabetes, hypertension, and surgeon experience. The EOR, namely, subtotal tumor resection with remnant and calcification, was significantly different. Calcification of the tumor results in increased spinal cord manipulation, which should be considered when microsurgical resection is the goal. In planning the surgical procedure, CT can be very helpful to establish plans for a safe and optimal surgical approach. Tumor recurrence had an impact on clinical outcome and level of independency as expressed by a higher ECOG score.

\section{Functional Outcome}

Poor functional outcome has been reported to be between $2 \%$ and $20 \% .^{8,12-14,17-22}$ Moreover, factors leading to poor functional outcome after surgery were tumor calcification, anterior dural attachment, tumoral adherence to the spinal cord, poor preoperative status, and advanced age..$^{8,13}$, 14,18,19,21 Poor functional outcome in our investigated patient population was evident in 6 patients $(5 \%)$. In addition to known variables such as localization, EOR, histology and thus rate of tumor recurrence, sex, and age, we found some additional factors affecting clinical outcome, namely, obesity, ASA score, and the effect of previous surgery. These aspects should be considered when performing surgery in patients with spinal meningiomas. Ultimately, we showed that patient outcome was associated with the length of hospital stay and was prolonged in patients with neurological deterioration, which is not only of medical interest but also of financial interest (Fig. 3).

\section{Conclusions}

Our results reflect a good functional outcome after microsurgical resection of spinal meningiomas. In addition to known factors, we found that obesity, surgeon experience, and surgical time affect functional outcomes and complication rates.

\section{References}

1. Helseth A, Mørk SJ. Primary intraspinal neoplasms in Norway, 1955 to 1986 . A population-based survey of 467 patients. J Neurosurg. 1989;71(6):842-845.

2. Duong LM, McCarthy BJ, McLendon RE, et al. Descriptive epidemiology of malignant and nonmalignant primary spinal cord, spinal meninges, and cauda equina tumors, United States, 2004-2007. Cancer. 2012;118(17):4220-4227.

3. Kshettry VR, Hsieh JK, Ostrom QT, et al. Descriptive epidemiology of spinal meningiomas in the United States. Spine (Phila Pa 1976). 2015;40(15):E886-E889.

4. Ostrom QT, Cioffi G, Gittleman H, et al. CBTRUS statistical report: primary brain and other central nervous system tumors diagnosed in the United States in 2012-2016. Neuro Oncol. 2019;21(suppl 5):v1-v100.

5. Rohringer M, Sutherland GR, Louw DF, Sima AA. Incidence and clinicopathological features of meningioma. J Neurosurg. 1989;71(5 Pt 1):665-672.

6. Westwick HJ, Shamji MF. Effects of sex on the incidence and prognosis of spinal meningiomas: a Surveillance, Epidemiology, and End Results study. J Neurosurg Spine. 2015;23(3):368-373.

7. Sadetzki S, Flint-Richter P, Ben-Tal T, Nass D. Radiationinduced meningioma: a descriptive study of 253 cases. $J$ Neurosurg. 2002;97(5):1078-1082.

8. Solero CL, Fornari M, Giombini S, et al. Spinal meningiomas: review of 174 operated cases. Neurosurgery. 1989;25(2): 153-160.

9. Oken MM, Creech RH, Tormey DC, et al. Toxicity and response criteria of the Eastern Cooperative Oncology Group. Am J Clin Oncol. 1982;5(6):649-655.

10. Simpson D. The recurrence of intracranial meningiomas after surgical treatment. J Neurol Neurosurg Psychiatry. 1957; 20(1):22-39.

11. Klekamp J, Samii M. Surgical results for spinal meningiomas. Surg Neurol. 1999;52(6):552-562.

12. Gottfried ON, Gluf W, Quinones-Hinojosa A, et al. Spinal meningiomas: surgical management and outcome. Neurosurg Focus. 2003;14(6):e2.

13. Roux FX, Nataf F, Pinaudeau M, et al. Intraspinal meningiomas: review of 54 cases with discussion of poor prognosis factors and modern therapeutic management. Surg Neurol. 1996;46(5):458-464.

14. Levy WJ Jr, Bay J, Dohn D. Spinal cord meningioma. J Neurosurg. 1982;57(6):804-812.

15. Wigertz A, Lönn S, Mathiesen T, et al. Risk of brain tumors associated with exposure to exogenous female sex hormones. Am J Epidemiol. 2006;164(7):629-636.

16. Wiemels J, Wrensch M, Claus EB. Epidemiology and etiology of meningioma. J Neurooncol. 2010;99(3):307-314.

17. Schaller B. Spinal meningioma: relationship between histological subtypes and surgical outcome? J Neurooncol. 2005; 75(2):157-161.

18. Sandalcioglu IE, Hunold A, Müller O, et al. Spinal meningiomas: critical review of 131 surgically treated patients. Eur Spine J. 2008;17(8):1035-1041.

19. Raco A, Pesce A, Toccaceli G, et al. Factors leading to a poor functional outcome in spinal meningioma surgery: remarks on 173 cases. Neurosurgery. 2017;80(4):602-609.

20. Hua L, Zhu H, Deng J, et al. Clinical and prognostic features of spinal meningioma: a thorough analysis from a single neurosurgical center. J Neurooncol. 2018;140(3):639-647.

21. Setzer M, Vatter H, Marquardt G, et al. Management of spinal meningiomas: surgical results and a review of the literature. Neurosurg Focus. 2007;23(4):E14.

22. Voldřich R, Netuka D, Beneš V. Spinal meningiomas: is Simpson grade II resection radical enough? Acta Neurochir (Wien). 2020;162(6):1401-1408.

23. Zhu Q, Qian M, Xiao J, et al. Myelopathy due to calcified meningiomas of the thoracic spine: minimum 3-year followup after surgical treatment. J Neurosurg Spine. 2013;18(5): 436-442.

24. Nakamura M, Tsuji O, Fujiyoshi K, et al. Long-term surgical outcomes of spinal meningiomas. Spine (Phila Pa 1976). 2012;37(10):E617-E623.

25. Bayoumi AB, Laviv Y, Karaali CN, et al. Spinal meningiomas: 61 cases with predictors of early postoperative surgical outcomes. J Neurosurg Sci. 2020;64(5):446-451.

26. Cheung ZB, Vig KS, White SJW, et al. Impact of obesity on surgical outcomes following laminectomy for spinal metastases. Global Spine J. 2019;9(3):254-259.

27. Cao J, Kong L, Meng F, et al. Impact of obesity on lumbar spinal surgery outcomes. J Clin Neurosci. 2016;28:1-6. 
28. Patel N, Bagan B, Vadera S, et al. Obesity and spine surgery: relation to perioperative complications. J Neurosurg Spine. 2007;6(4):291-297.

29. Mirimanoff RO, Dosoretz DE, Linggood RM, et al. Meningioma: analysis of recurrence and progression following neurosurgical resection. J Neurosurg. 1985;62(1):18-24.

\section{Disclosures}

The authors report no conflict of interest concerning the materials or methods used in this study or the findings specified in this paper.

\section{Author Contributions}

Conception and design: Behmanesh. Acquisition of data: Behmanesh, Kilinc. Analysis and interpretation of data: Behmanesh. Drafting the article: Kilinc. Reviewed submitted version of manuscript: Behmanesh, Marquardt. Approved the final version of the manuscript on behalf of all authors: Behmanesh. Statistical analysis: Setzer. Administrative/technical/material support: Setzer, Keil, Dubinski, Bruder. Study supervision: Seifert.

\section{Correspondence}

Bedjan Behmanesh: University Hospital, Frankfurt, Germany. bedjan.behmanesh@gmail.com. 